
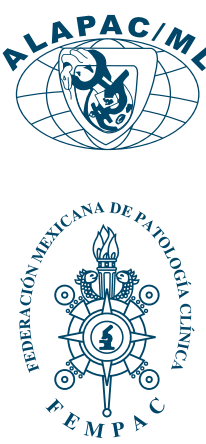

Palabras clave: Arbovirus, virus de Mayaro, zoonosis.

Keywords:

Arbovirus, Mayaro virus, zoonosis.

* Coordinador clínico de turno de la Unidad Médica de Alta Especialidad de Mérida, Yucatán. Instituto Mexicano del Seguro Social. Responsable Sanitario del Banco de Sangre del Instituto Médico Panamericano, S.A. de C.V.

Correspondencia: Dr. José Roberto Barba Evia

Calle 37 A, Núm. 318, entre 24 y 26.

Fraccionamiento Monte Albán, 97114, Mérida Yucatán, México.

E-mail: dr_barba@

hotmail.com

Recibido:

21/02/2020

Aceptado:

13/03/2020

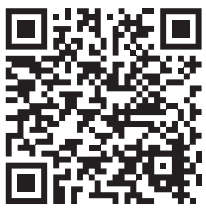

\title{
Virus de Mayaro. ¿La nueva amenaza?
}

\author{
Mayaro virus. The new threat?
}

\author{
Barba Evia José Roberto*
}

\section{RESUMEN}

Desde el año 2000, nuestro país se ha visto afectado por brotes de algunos arbovirus, principalmente por aquéllos que causan dengue (DENV), chikunguña (CHIKV) y zika (ZIKV), los cuales, a partir de que han sido detectados los primeros casos, no ha sido posible su erradicación. De la misma manera, como ya ocurrió con los virus antes mencionados, el virus causante de la fiebre Mayaro (MAYV) es, sin duda alguna, otra potencial amenaza para introducirse y establecerse en México, principalmente debido a que las infecciones virales transmitidas por vectores artrópodos hematófagos (los cuales en su gran mayoría son mosquitos de diversas especies) son difíciles de controlar y de evitar su propagación, pues el hábitat de estos vectores es muy amplio, por lo que sólo es posible contener su reproducción a través de programas de fumigación, así como educando a la población afectada mediante la adopción de medidas preventivas que consisten básicamente en la eliminación de objetos que acumulen agua, así como el uso de mosquiteros. Es difícil conocer la incidencia de la fiebre de Mayaro en la población mexicana, debido, por una parte, a que esta infección presenta un cuadro clínico similar a otros virus de la familia Togaviridae, en especial, del género alfavirus, lo que puede generar un subregistro de casos principalmente por la falta de confirmación del agente causal (mediante resultados de serología infecciosa) y, por otra parte, está la corta duración de la viremia en esta infección, lo cual puede limitar la utilidad del laboratorio clínico.

\section{ABSTRACT}

Since 2000, our country has been affected by outbreaks of some arboviruses, mainly those that cause dengue (DENV), chikunguña (CHIKV) and zika (ZIKV), which once the first cases were detected has not been possible eradication. In the same way as with the aforementioned viruses, the virus causing Mayaro fever (MAYV) is undoubtedly another potential threat to be introduced and established in Mexico, this mainly due to viral infections transmitted by arthropod vectors hematophages (which are mostly mosquitoes of various species), are difficult to control and prevent their spread, mainly because the habitat of these vectors is very wide, so it is only possible to contain their reproduction through programs of fumigation, as well as educating the affected population by adopting preventive measures that basically consist in the elimination of objects that accumulate water as well as the use of mosquito nets. On the other hand, it is difficult to know the incidence of Mayaro fever in the Mexican population, on the one hand because this infection presents a clinical picture similar to other viruses of the Togaviridae family, especially of the genus alphavoirus, which can lead to under-registration of cases mainly due to the lack of confirmation through results of infectious serology that confirms or discards the causative agent, and on the other hand there is the short duration of viremia in this infection, which may limit the usefulness of the clinical laboratory.

\section{INTRODUCCIÓN}

A ctualmente, la presencia de enfermedades emergentes desmiente la utopía acerca de la «conquista definitiva de la enfermedad infecciosa», lo que deja en claro que hay deficiencias en la prevención, manejo y solución de éstas. Gran parte de estas enfermedades emergentes son la zoonosis, término que se refiere a que el agente patógeno causante de la enfermedad (bacterias, virus, parásitos y, en raras ocasiones, hongos) tiene un reservorio en un animal silvestre y, a partir de éste, se puede transmitir directamente al ser humano o a los animales domésticos, los que, a su vez, pueden también transmitirlo al humano. Alrededor del $62 \%$ de los patógenos humanos son de origen zoonótico, cuyo grueso de las enfermedades emergentes son los de origen animal. Los patógenos zoonóticos emergentes con respecto a su transmisión a los humanos pueden dividirse en dos grupos: el primero se caracteriza con transmisión como un evento raro, mientras que el segundo grupo abarca aquellos patógenos que se transmiten directamente o a través de vectores a la población humana, siendo los animales silvestres casi siempre el reservorio de la infección. ${ }^{1}$ 
A partir de lo antes mencionado, desde el año 2000 y durante los últimos 20 años, México se encuentra en lucha constante contra las enfermedades infecciosas transmitidas por vector, ya que está presente la infección por el dengue (DENV) con la presencia de brotes anuales; para finales de 2014, se reportaron los primeros casos de infección por chikunguña (CHIKV), y para 2015, los primeros casos de y zika (ZIKV). ${ }^{2}$

Los arbovirus (virus transmitidos por artrópodos) son un grupo taxonómicamente heterogéneo que se componen por más de 500 virus. Aproximadamente de éstos, 150 causan enfermedad en los humanos, debido a que son transmitidos entre vertebrados susceptibles a través de una gran variedad de vectores artrópodos hematófagos como mosquitos, garrapatas, pulgas, entre otros. Por la razón expuesta antes, es que la arbovirosis se ha convertido en un dilema mundial muy difícil de controlar, debido a que los vectores transmisores de estas enfermedades, principalmente los mosquitos, se encuentran distribuidos por todo el mundo, siendo muy complejo limitar su reproducción y distribución, pues solamente se ha logrado restringir mediante el uso de insecticidas, así como por las medidas de prevención a través de la educación en las comunidades afectadas. ${ }^{3-6}$

La mayoría de los arbovirus clínicamente significativos provienen de tres familias principales: Togaviridae, Flaviviridae y Bunyaviridae (Figura 1). Una manera de clasificar a estos virus es de acuerdo con el tipo de síndrome que ocasionan al ser humano (Figura 2). 3-6

En las últimas décadas, los virus de la familia Togaviridae $y$, en especial los que pertenecen al género alfavirus, han sido objeto de múltiples estudios, debido a su potencial como agentes causales de ciertas zoonosis (algunas de las cuales han generado epizootias y epidemias recurrentes). Los alfavirus tienen una amplia distribución en todos los continentes, excepto la Antártida. En humanos, los alfavirus causan una variedad de enfermedades que van desde síndromes inespecíficos parecidos a la gripe y que pasan por la artritis o la erupción cutánea hasta la encefalitis severa, los cuales pueden llegar a ser incluso fatales. Además de causar enfermedades humanas graves, estos virus producen epizootias acompañadas de altas tasas de mortalidad en equinos y en otros animales domésticos. La emergencia y reemergencias de las zoonosis causados por estos virus se debe a ciertos factores conocidos, como mutaciones ocurridas entre hospederos y antrópicas (cambios en el uso de la tierra por actividades turísticas y económicas), cambio climático, crecimiento poblacional, malas condiciones sanitarias, alteración de los ecosistemas, deforestación, desplazamiento de poblaciones, así como la invasión de humanos y animales domésticos en los hábitats de los artrópodos transmisores. ${ }^{3,7-9}$

\section{FIEBRE DE MAYARO}

A esta infección endémica de la Amazonia se le conoce comúnmente por las poblaciones nativas como la «gripe de la selva». Como su nombre lo indica, se trata de una enfermedad febril exantemática, benigna, autolimitada, y que se caracteriza por la presencia de artralgias severas, cuyos signos y síntomas son similares a las infecciones por CHIKV, DENV y fiebre amarilla (YFV), razón por la cual se incluye dentro de las enfermedades de notificación obligatoria. ${ }^{10-12}$

La fiebre de Mayaro se trata de una zoonosis producida por MAYV, el cual es un arbovirus de la familia Togaviridae y del género alfavirus, donde se incluyen 29 virus, los cuales se clasifican en siete complejos antigénicos, entre ellos, los agentes causantes de las encefalitis

\begin{tabular}{|c|c|c|c|}
\hline & Arbovirus: familias & & \\
\hline Togaviridae & Flaviviridae & Bunyaviridae & Figura 1: \\
\hline $\begin{array}{l}\text { - Chikunguña (CHIKV) } \\
\text { Sudáfrica central-este } \\
\text { África del oeste } \\
\text { Asia } \\
\text { Océano Índico } \\
\text { Mayaro } \\
\text { Sudáfrica central-este } \\
\text { África del oeste } \\
\text { Asia }\end{array}$ & \begin{tabular}{|c} 
- Dengue (DENV) \\
DENV1 \\
DENV2 \\
DENV3 \\
DENV4 \\
\\
- Virus de Zika (ZIKV) \\
Estirpe africana \\
Estirpe asiática \\
\\
Fiebre amarilla
\end{tabular} & $\begin{array}{l}\text { - Hantavirus } \\
\text { Encefalitis de } \\
\text { La Crosse } \\
\text { Fiebre Orepuche }\end{array}$ & $\begin{array}{l}\text { Clasificación de los arbovirus. } \\
\text { Tomado y modificado: Cárdenas } \\
\text { MM, Pech SN, Arias LJ. Fiebre } \\
\text { Mayaro: enfermedad emergente } \\
\text { al acecho. Ciencia Humanismo } \\
\text { Salud. 2016; } 3 \text { (3): 32-40. Barón CA, } \\
\text { Munguía MID. Dengue, chikunguña, } \\
\text { zika y Mayaro, amenazas para la } \\
\text { salud en Honduras. Rev Fac Cienc } \\
\text { Méd. 2017: 44-57. Arredondo GJ, } \\
\text { Méndez HA, Medina CH. Arbovirus } \\
\text { en Latinoamérica. Acta Pediatr Mex. } \\
\text { 2016; } 37 \text { (2): 111-131. }\end{array}$ \\
\hline
\end{tabular}




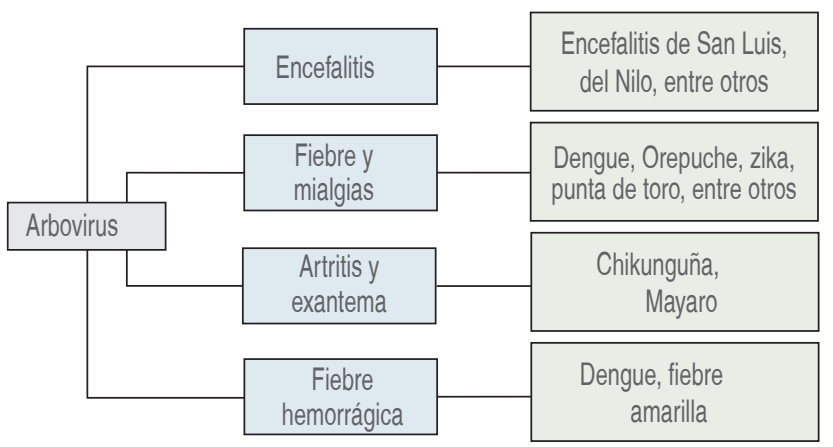

Figura 2: Clasificación de acuerdo con el síndrome que causa. Tomado de: Arredondo GJ, Méndez HA, Medina CH. Arbovirus en Latinoamérica. Acta Pediatr Mex. 2016; 37 (2): 111-131.

equinas venezolanas del este y del oeste, la fiebre de chikunguña, y los virus O'nyon-nyong, del río Ross, del bosque de Barmah y Sindbis. Este virus pertenece al complejo antigénico del virus del bosque Semliki, que incluye alfavirus mundiales tanto de Europa como de América. ${ }^{2-3,5-8,11-12}$

El MAYV tiene $70 \mathrm{~nm}$ de diámetro, protegido por una cápside icosaédrica y es envuelto por una membrana lipídica. Como todos los alfavirus, posee material genético conformado por ARN monocatenario de sentido positivo, con una longitud aproximada de 11,429 nucleótidos flanqueada por dos regiones: la genómica o subgenómica 5'(7-metilguanilato [m7G]), la cual constituye dos tercios del genoma en un marco de lectura abierto de 7,425 nucleótidos iniciada por un codón ATG de inicio y terminado en un codón TAG de detección que sirve para codificar cuatro proteínas no estructurales denominadas nsP1, nsP2, nsP3 y nsP4; y la región subgenómica 3' (poli-A), la cual representa un tercio del genoma codificada por 4,327 nucleótidos y sirve para la producción de cinco proteínas estructurales denominadas C, 6K/TF, E3, E2 y E1 (las últimas tres constituyen las proteínas de la envoltura viral). De manera similar a otros alfavirus, el ARN del MAYV posee un codón de paro al final del gen nsP3, y en una frecuencia baja (5-20\%), puede ocurrir una traducción de lectura, resultando en productos nsP1-4. La región no estructural suele ser más conservada que la región estructural entre los diferentes virus de este género, encontrándose al menos un $60 \%$ similar en las secuencias de aminoácidos en la primera subregión y de $45 \%$ en comparación con la región subgenómica (Figura 3).4,7,12-16

El genoma de este virus junto con la proteína C (proteína del núcleo) conforman una nucleocápside icosaédrica, en tanto que las proteínas de envoltura celular que rodea la cápside están formadas por los restos de la membrana plasmática de las células hospederas y por dos glucoproteínas: E1 y E2 (espículas); usualmente, E3 se desprende de la mayoría de los alfavirus. Como cualquier virus que posee material genético tipo ARN, el MAYV presenta una gran adaptabilidad debido a su gran capacidad de mutaciones, lo que aumenta la probabilidad de adaptación a nuevos organismos, tanto vertebrados como invertebrados, los cuales pueden servir de hospederos. De acuerdo con su región de identificación, se han encontrado múltiples cepas derivadas, cuyos serotipos se agrupan en tres linajes diferentes: Sudáfrica central-este, África del oeste y Asia. Filogenéticamente, a este virus se le han identificado tres distintos genotipos designados como D, L y N. El genotipo D tiene una mayor extensión geográfica (Trinidad, Perú, Colombia, Surinam, Guyana, Venezuela, Argentina, Bolivia y Brasil), mientras que para el genotipo L (región amazónica de Brasil) se ha postulado que se originó como consecuencia de la introducción del virus en especies locales, entre los cuales los arbovirus se han mantenido circulando. No obstante, a esta alta tasa de mutación, la cual incrementa la posibilidad de replicarse en distintos hospederos, los alfavirus son específicos en cuanto a los vectores empleados. La clave de esta especificidad probablemente radique en los receptores localizados en el intestino medio (mesenterón) del mosquito hematófago, lo que le permite atravesar diferentes barreras dentro del vector y pasar al sistema circulatorio. $2,4-5,7,12-14,17$

Este virus circula en un ciclo zoonótico y se transmite entre vertebrados susceptibles, principalmente por la picadura de un vector infectado hacia el huésped, siendo en el $80 \%$ de éstos los mosquitos selváticos de la familia Culicidae y Haemagogus janthinomys, sin embargo, los géneros Culex, Sabethes, Psorophora, Coquillettidia, Aedes aegypti, Aedes scapularis, Aedes albopictus y Haemagogus Williston también son considerados como vectores eficientes. Varios de los hospederos vertebrados, principalmente primates, roedores y aves, son considerados como reservorios, aunque su papel exacto en mantener el virus, en la actualidad, no se conoce del todo. ${ }^{3-5,7,11,17,18}$

\section{BREVE HISTORIA}

Algunos autores proponen que el MAYV fue introducido en el Nuevo Mundo hace 2,000 a 3,000 años, como consecuencia de la divergencia de los complejos antigénicos entre los virus del bosque Semliki y Sindbis, jugando un papel importante en su dispersión tanto las aves migratorias como los humanos. ${ }^{7}$

Entre 1904 y 1914, estudios retrospectivos permitieron evidenciar la infección por MAYV en sueros recolectados 


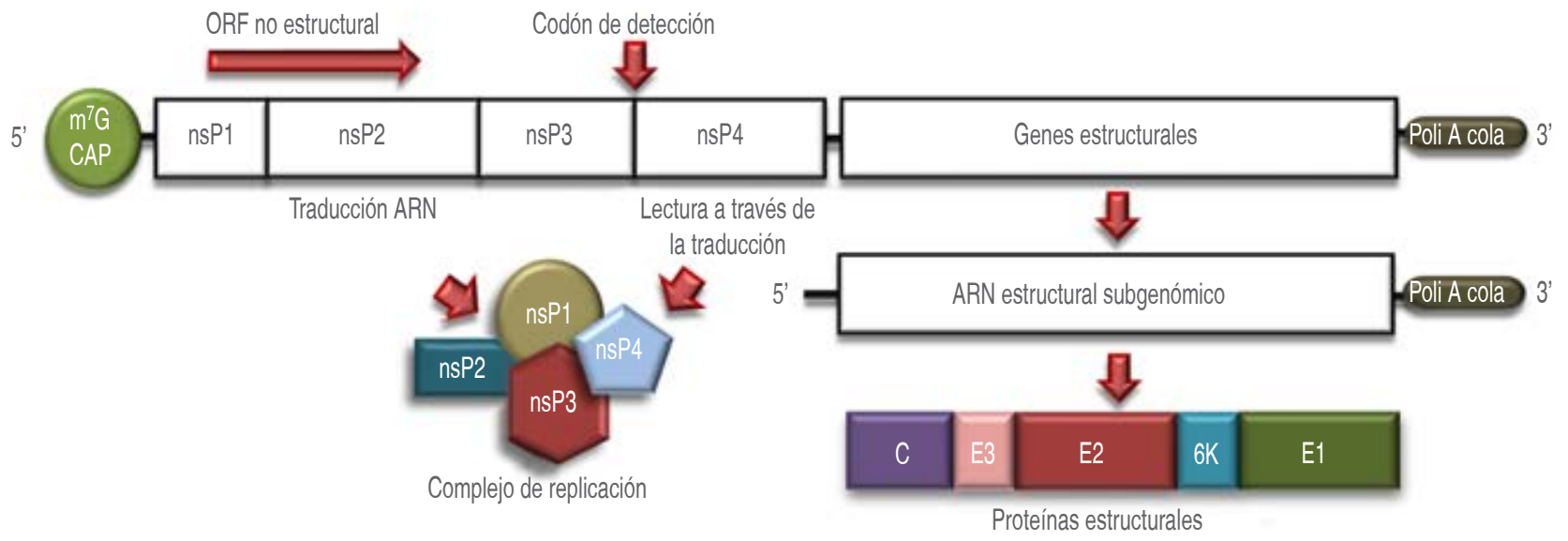

Figura 3: Esquema de la organización del genoma del MAYV y su complejo de replicación.

Tomado y modificado de: Alves ED, Lopes da Fonseca BA. Will Mayaro virus be responsible for the next outbreak of an arthropod-borne virus in Brazil? Braz J Infect Dis. 2017; 21 (5): 540-544.

durante la construcción del canal de Panamá. ${ }^{19}$ En 1954, se inició la historia epidemiológica de la infección con el MAYV, cuando se realizó el primer aislamiento de este virus en cinco campesinos con fiebre en el condado de Mayaro (Trinidad y Tobago), de donde debe su nombre. Desde entonces, como ya se ha mencionado, este virus ha sido aislado en varios países sudamericanos. ${ }^{2,3,6,10,13,18}$

En 1955, se describieron las primeras epidemias en Brasil, Bolivia y Surinam, permaneciendo restringidos estos brotes hasta1991, principalmente en Brasil. ${ }^{3,13}$ Otros reportes de casos de la enfermedad se dieron en Colombia (1958-1960), Bolivia (1959) y Perú (1965). ${ }^{19}$

En 1967, la Organización Mundial de la Salud (OMS) describió a los arbovirus como un grupo de virus que existe en la naturaleza, debido principalmente a la transmisión biológica por artrópodos hematófagos entre huéspedes vertebrados susceptibles. ${ }^{4}$

Entre 1977 y 1978, ocurrió un brote en Brasil, el cual coincidió con una epidemia de fiebre amarilla, en donde se logró aislar el MAYV del mosquito Haemagogus janthinomys (el vector principal de la fiebre amarilla). ${ }^{3,7}$

En 1997, en Estados Unidos de América se reportaron casos importados de Perú y Bolivia, así como en Ecuador (1997), Guayana Francesa (1998) y Venezuela (2000). ${ }^{19}$ En México, en 2001, se estudiaron a 35 pacientes con enfermedad febril hemorrágica; de éstos, dos casos fueron positivos para infección por MAYV en los puertos de Tamaulipas y Veracruz. En ambos casos, los pacientes presentaron datos de sangrado por plaquetopenia e ictericia, y además uno de ellos desarrolló datos de en- cefalopatía durante 30 días, después de los cuales murió, constituyéndose como el único caso mortal descrito hasta la fecha por esta infección. ${ }^{3,6,7}$

En 2008, el virus reemergió al norte de Brasil, y para 2010, se presentó un brote de 77 casos en Venezuela. 3,4,14 Desde 2011, el MAYV fue incluido como enfermedad de notificación en Brasil, debido a que es una causa frecuente de síndrome febril. ${ }^{17}$

En 2015, se reportó el primer caso confirmado en Haití en un niño de ocho años que provenía de una zona rural. Este paciente presentó dolor abdominal y fiebre sin presencia de erupciones cutáneas ni tampoco de conjuntivitis. Fue diagnosticado con coinfección por dengue y Mayaro, despertando con ello las alertas epidemiológicas. $2,5,19$

En 2018, se notificaron 35 casos en Perú y, en 2019, se confirmaron en esta misma nación dos casos más. ${ }^{20}$

\section{CICLO VITAL}

El MAYV posee un ciclo vital completo, el cual es similar al de otros arbovirus, ya que durante el ciclo selvático la transmisión es por medio de la inoculación del virus, y ésta se mantiene entre mosquitos vectores y diferentes especies de reservorios, principalmente lagartos, primates, aves migratorias, marsupiales, caballos y roedores, los cuales sufren la enfermedad natural alcanzando altos niveles de viremia (umbral de infección) sin presencia de síntomas, para finalmente regresar nuevamente al vector, por lo que el MAYV se mantiene en la naturaleza. Este tipo 
de transmisión se le conoce como biológica propagativa (ya que existe multiplicación sin desarrollo del agente en el vector). Sin embargo, al humano se le considera como un huésped incidental, ya que se transmite de manera accidental cuando éste invade el hábitat de los reservorios silvestres (Figura 4). 3,5,14,15

Los mosquitos hembras hematófagas adquieren el virus al alimentarse de un hospedero infectado y que presenta viremia alta. Una vez que el virus se encuentra en el vector, éste infecta las células epiteliales del intestino medio (mesentrón) del mosquito, en donde se multiplica para atravesar la lámina basal Ilegando a la hemolinfa, para que por medio de ésta pueda migrar hacia las glándulas salivales y allí permanecerá hasta que sea inoculado al momento de que el mosquito hembra nuevamente pique al reservorio para alimentarse, y de esta manera, se repita el ciclo.

Comprender la entrada de un virus en una célula es un paso clave para comprender la infección y, en última instancia, en la creación de una intervención para obstruir la actividad viral. Los mecanismos por los cuales los prototipos de alfavirus ingresan a las células humanas se conocen desde los inicios de la década de 1990. Las glicoproteínas transmembranales de la envoltura E1 y E2 corresponden a las espículas de envoltura que cubren la superficie viral y son antigénicas. Los antígenos E2 son capaces de inducir anticuerpos neutralizantes, los cuales son esenciales para la eficiente respuesta inmune en el hospedero infectado. La replicación viral en el humano se da cuando el virus ingresa en la célula huésped a través de una interacción ligando-receptor, siendo la glucoproteína E2 la responsable de este contacto entre las partículas virales y la superficie celular. Una vez ocurrida esta interacción, la partícula viral es introducida mediante un mecanismo de endocitosis por medio de la vesícula. Posteriormente, la membrana viral se fusiona con el endosoma, proceso mediado por la glucoproteína viral E1, lo cual es dependiente del $\mathrm{pH}$, así como de la concentración de iones intracelulares; esto favorece la replicación viral, ya que permite la liberación de la nucleocápside hacia el citoplasma celular. Las proteínas estructurales se producen después de la traslación de un ARN de transcripción subgenómico. Siguiendo a la expresión de proteínas estructurales, el ARN viral es incorporado a las proteínas de la cápside y de la envoltura, que se procesan durante su paso a través del aparato de Golgi para ser insertadas en la membrana plasmática de donde el virus adquiere su envoltura, liberando partículas potencialmente infectantes para las células susceptibles. Las células infectadas mueren debido al aumento en la permeabilidad de la membrana celular, así como por los cambios en las concentraciones iónicas, alterando la actividad enzimática celular, lo que

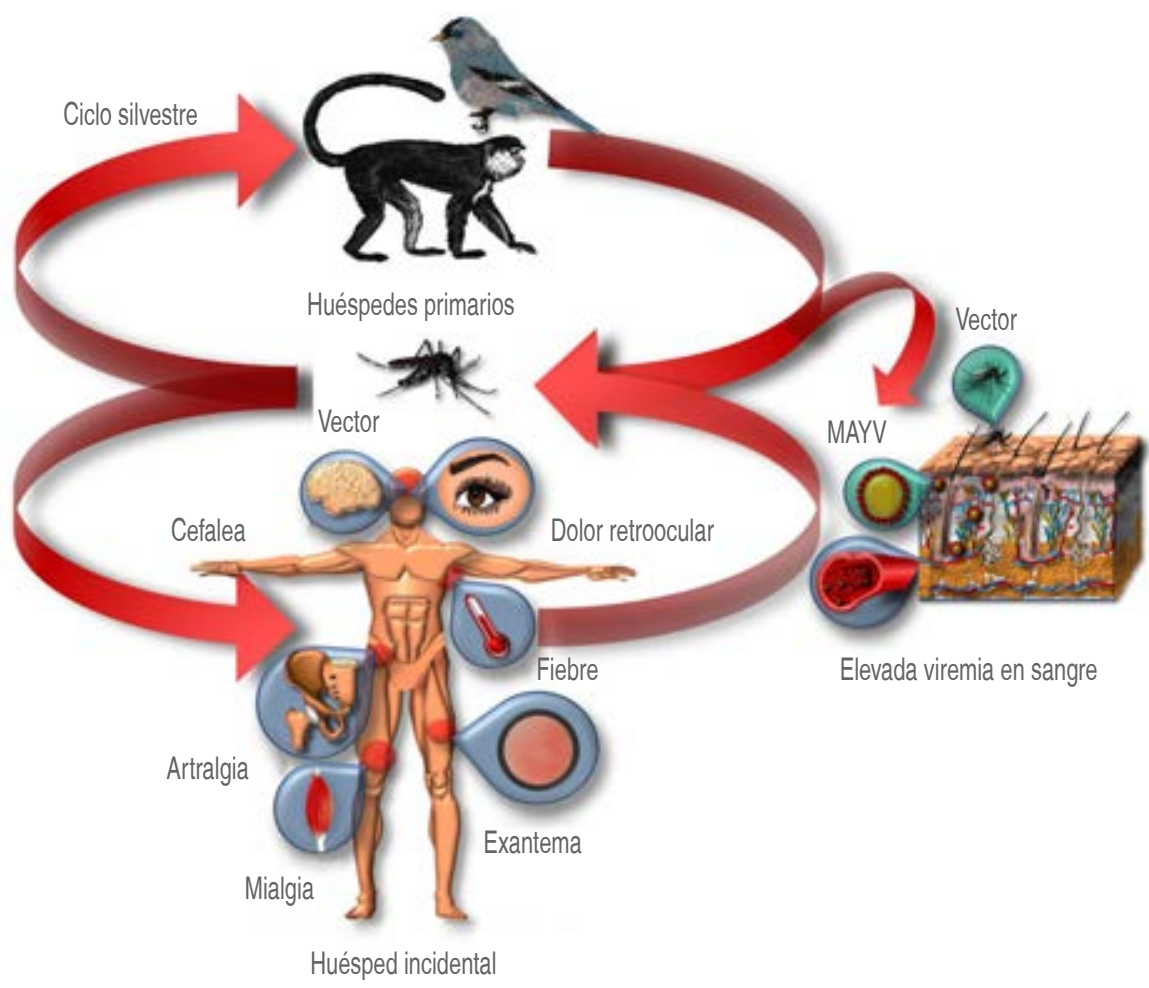

Figura 4:

Ciclo vital del virus de Mayaro. 
favorece la traducción del ARN viral sobre el ARNm celular, impidiendo de esta manera la reconstrucción y el mantenimiento celular. ${ }^{2,5,7,12,13,15}$

Tras la infección viral, se genera una respuesta inmunológica debido a la activación de varias vías de señalización celular, inicialmente por el sistema inmune innato y posteriormente mediante un control más específico y permanente por parte del sistema inmune adaptativo. El sistema inmune innato es una respuesta no específica ante la presencia de patógenos o al estrés celular. Existen tres vías de señalización que componen este primer sistema de defensa:

a) Receptores tipo Toll (son proteínas transmembrana que reconocen proteínas o genomas patógenos), los cuales desencadenan la activación de algunos factores de transcripción para expresar citosinas y otros genes inmunosensibles.

b) Receptores tipo NOD (dominio de oligomerización y unión a nucleótidos), los cuales son sensores antimicrobianos intracelulares y se relacionan con la activación de caspasas proinflamatorias intracelulares.

c) Receptores tipo RIG (gen I inducido por ácido retinoico), los cuales son complejos intracelulares que reconocen fragmentos del genoma en el citosol.

Estas tres señales culminan de manera directa o indirecta con la expresión de genes de inmunidad sensibles, como citosinas, quimiocinas, interferones o ISG (genes estimulados por interferón). El virus dentro de la célula comienza su proceso de replicación y producción de nuevas proteínas virales, algunas de las cuales se degradarán en pequeños péptidos que serán capturados por moléculas del complejo mayor de histocompatibilidad $(\mathrm{CMH})$, siendo el $\mathrm{CMH}$ clase I el encargado de presentar el péptido antigénico a linfocitos T (CD8+). Estos linfocitos aumentan su número en las etapas tempranas de la infección para reconocer células infectadas, liberando gránulos citotóxicos que inducen a la muerte celular. El $\mathrm{CMH}$ clase II de las células presentadoras del antígeno activan las células CD4+, las cuales expresan citosinas y quimiocinas y pueden ser agrupadas como células Th1, Th2, Th17 o Treg, dependiendo del tipo de citosina secretada. La producción de citosinas puede controlar la infección viral, ya sea induciendo una respuesta celular antiviral o a través de la señalización para la producción de anticuerpos. La respuesta inmune adaptativa es activa y efectiva durante una semana o más después de la infección, esto debido a que la viremia en la infección por MAYV es corta (generalmente dura de dos a siete días después del comienzo de los síntomas). ${ }^{16}$
El aumento en el crecimiento de la población, la intervención y urbanización de áreas enzoóticas, y la expansión del área de influencia proporcionan suficientes datos para afirmar que los casos epizoóticos ocurren cuando los humanos ingresan en el nicho de los reservorios y vectores naturales, infectándose con el virus cuando son picados por artrópodos portadores de Haemagogus. ${ }^{7}$

\section{CUADRO CLÍNICO}

Un factor considerado de riesgo es estar en contacto reciente con zonas selváticas tropicales húmedas o boscosas. ${ }^{2} \mathrm{Al}$ día de hoy, poco se sabe acerca de la fisiopatología de la fiebre de Mayaro, pero una vez que se establece la infección, el virus tiene un periodo de incubación. En el ser humano, éste es relativamente corto, el cual se ha descrito que varía entre tres y 12 días. La viremia se presenta durante la fase aguda y dura de dos a siete días. Posteriormente, se producen los anticuerpos IgM (durante el tercer o cuarto día), que es cuando puede detectarse una infección reciente en el suero. $3,7,13,19$

Como ocurre con otras arbovirosis, la infección con MAYV produce signos y síntomas inespecíficos en su fase inicial similares a los presentados en la fiebre amarilla, dengue y chikunguña, lo que puede disminuir la certeza del diagnóstico; sin embargo, según la enfermedad, se pueden encontrar patrones indicadores, signos y síntomas más notorios de padecerse (Tabla 1), lo que permite reducir el grado de sospecha y volver a diagnósticos más acertados. ${ }^{4,7}$

De acuerdo con lo anterior, la fiebre de Mayaro se manifiesta con un inicio abrupto de síndrome febril $(\geq$ $39^{\circ} \mathrm{C}$ ), cuya duración es corta (tres a siete días), acompañada de erupción cutánea de tipo maculopapular (en pecho, piernas, espalda, brazos y, menos frecuente, en cara) y artralgia (más frecuente en articulaciones pequeñas de las manos y pies, hombros, rodillas o en grandes articulaciones y, en raras ocasiones, la cadera), la cual en el $54 \%$ de los pacientes puede ser severa, debilitante, incapacitante y de duración prolongada (meses a un par de años). Los macrófagos (células diana durante la replicación viral) juegan un papel importante en el desarrollo de la artritis por la apoptosis debido a la participación de citoquinas proinflamatorias y quimiocinas (IL-6, IL-8, RANTES, IL-1 $\beta$ y expresión de TNF) de manera directamente proporcional al número de macrófagos muertos infectados por MAYV. Otros síntomas que se pueden presentar incluyen: cefalea, mialgia, dolor retrocular, escalofríos, mareos, náuseas, fotofobia, anorexia, tos, eflorescencia, poliuria, vértigo y linfadenopatía cervical e inguinal, leucopenia $(2,500 /$ 
Tabla 1: Comparación sintomatología arbovirus.

\begin{tabular}{|c|c|c|c|c|c|c|}
\hline \multirow[b]{2}{*}{ Enfermedad síntoma/signo } & \multicolumn{3}{|c|}{ Dengue } & \multirow[b]{2}{*}{ Chikunguña } & \multirow[b]{2}{*}{ Zika } & \multirow[b]{2}{*}{ Mayaro } \\
\hline & Sin signos de alarma & $\begin{array}{l}\text { Con signos de } \\
\text { alarma }\end{array}$ & Grave & & & \\
\hline Fiebre & +++ & ++ & ++ & +++ & + & + \\
\hline Eflorescencia macopapular & + & + & + & ++ & +++ & + \\
\hline Artritis 0 artralgias & + & + & + & +++ & + & ++ \\
\hline Conjuntivitis no purulenta & & & & $+($ raro) & ++ & \\
\hline Mialgia o fatiga & + & + & + & ++ & ++ & + \\
\hline Cefalea & + & + & + & ++ & + & + \\
\hline Vómito & + & ++ & + & & & + \\
\hline Dolor retroocular & + & + & + & & + & + \\
\hline Anorexia & + & + & + & + & & \\
\hline Fotofobia & + & + & + & & & + \\
\hline Edema & + & + & +++ & + & ++ & \\
\hline Hemorragia & & + & +++ & & & \\
\hline Shock hipovolémico & & & +++ & & & \\
\hline Hepatomegalia & & + & + & & & \\
\hline Náuseas & + & + & + & & & + \\
\hline $\begin{array}{l}\text { Hiperemia } \\
\text { (faringe/conjuntiva) }\end{array}$ & + & + & + & + & & \\
\hline Mareos & + & + & + & & & + \\
\hline
\end{tabular}

Tomado de: Barón CA, Munguía MID. Dengue, chikunguña, zika y Mayaro, amenazas para la salud en Honduras. Rev Fac Cienc Méd. $2017: 44-57$.

$\mathrm{mm}^{3}$ ) y trombocitopenia y, menos frecuente, dolor abdominal, ictericia, diarrea, dolor de garganta, congestión nasal y tos, así como manifestaciones hemorrágicas y encefalitis, lo que ocasiona que, en muchos de los casos, la infección por MAYV pueda estar subdiagnosticada, como ya se mencionó. Estos síntomas duran alrededor de dos a 10 días. ${ }^{3-7,9,12,13,16,17,19}$

La infección por MAYV es considerada una enfermedad febril benigna con síntomas subletales y de resolución espontánea. Sin embargo, a pesar de esta baja tasa de mortalidad, la fiebre de Mayaro es una de las principales infecciones por arbovirus relevante para la salud pública en poblaciones rurales, debido a su creciente incidencia en humanos. $3,4,7,11$

\section{DIAGNÓSTICO}

El diagnóstico clínico se basa en la sintomatología inicial, sin embargo, como se ha mencionado previamente, suele ser muy confuso, esto debido a la similitud que existe con las infecciones producidas por otras arbovirosis. Para la confirmación de los casos, se debe realizar pruebas de laboratorio rápidas, sensibles y confiables, sobre todo en los casos en los que hay que tipificar un brote, ya que esto proveerá un mejor manejo de los pacientes. Debido a que la viremia del MAYV tiene una duración muy breve, hace muy difícil la identificación de este virus en muestras obtenidas después de la aparición de los síntomas, y es durante el tercer y cuarto día cuando se producen anticuerpos clase IgM, o bien la seroconversión de la lgG, lo que permite la detección de la infección (Figura 5). Dentro de los métodos de laboratorio más utilizados se encuentran la aplicación de pruebas serológicas inmunológicas y moleculares, en muestras de pacientes virémicos, entre los cuales se hallan los ensayos inmunoenzimáticos (EIAs), la fijación de complemento, la inhibición de hemaglutinación, la inmunofluorescencia y la reducción de placas por neutralización, con las que detectan anticuerpos clase IgM e IgG específicas; por métodos moleculares, se encuentra la amplificación del material genético del virus mediante la técnica de RT-PCR específica (se utilizan secuencias parciales del gen nsP1), sin embargo, el problema de ésta radica en que los ácidos nucleicos virales generalmente están presentes sólo de tres a seis días después de la infección. 3,5,7,8,15,19 
El principal problema de las pruebas serológicas inmunológicas radica en que los pacientes no acuden en la fase aguda de la infección, o bien se tienen muestras de sueros pareados, lo que generalmente incrementa los costos y tiempo para obtener resultados positivos. Para MAYV se forma parte del complejo Selmliki, el cual está compuesto por ocho virus (Bebaru, chikunguña, Mayaro, Getah, bosque Semliki, del río Ross, O'nyong-nyong y virus Una) que componen un grupo serológico incluido en el género alfavirus y que comparten algunos sitios antigénicos comunes, los cuales pueden generar reactividad cruzada con sueros inmunes policlonales entre las especies cuando son analizados mediante pruebas serológicas convencionales, como son la inhibición de hemaglutinación y la fijación del complemento. Debido a esto, las pruebas moleculares son más eficaces y específicas, aunque siempre hay que tener en cuenta que el virus está presente únicamente entre los días dos a seis posteriores a la infección.

Recientemente, ha sido utilizada la técnica combinada RT-PCR-ELISA, la cual combina la sensibilidad y la especificidad de las técnicas moleculares con la detección simplificada de la técnica ELISA, lo que permite diferenciar los alfavirus estrechamente relacionados, como el Mayaro, el de la encefalitis equina del este, del oeste y venezolana, el Mucambo, el Tonate, el del río Ross, el SFV, el O'nyong-nyong, el Aura, el Highlands J, el Fort Morgan y el Whataroa. $5,7,13$

Otras técnicas utilizadas son la inoculación in vivo del virus en el cerebro de ratones recién nacidos y las de la inoculación in vitro, la cual utiliza células de vertebrados en cultivo o células de invertebrados. ${ }^{3}$

\section{TRATAMIENTO}

No existe un antiviral contra el MAYV, por lo que los síntomas se manejan solamente mediante la prescripción inicial de analgésicos (acetaminofén, paracetamol), antiinflamatorios no esteroideos (ibuprofeno, naproxeno) y analgésicos para el alivio del dolor; la fiebre se trata de manera similar al manejo de la infección con CHIKV. En algunas ocasiones, está indicado el uso de corticosteroides cuya eficacia no ha sido totalmente probada. ${ }^{13,15}$

Dos vacunas no comerciales están disponibles, ambas probadas en experimentación preclínica. La primera fue generada a partir del uso de partículas inactivadas, para ella se usaron diferentes concentraciones de formalina; ésta mostró, con alguna eficacia, ser inmunogénica cuando se administró en ratones. La segunda es una vacuna viva atenuada; fue replicada en células vertebradas con mutaciones en los promotores subgenómicos y con control translacional en un sitio interno del ribosoma; ésta ha demostrado una gran producción de anticuerpos neutralizantes, así como un alto rango de sobrevivencia al utilizar ratones inmunocompetentes. ${ }^{13}$

\section{CONCLUSIÓN}

En los últimos años se ha observado la presencia de virosis antes desconocidas y enfermedades infecciosas que ya habían sido controladas en décadas anteriores; esto demuestra la fragilidad e ineficacia tanto de los controles sanitarios, como de los sistemas de vigilancia epidemiológica. En la gran mayoría de los casos, la historia natural de estas enfermedades infecciosas se

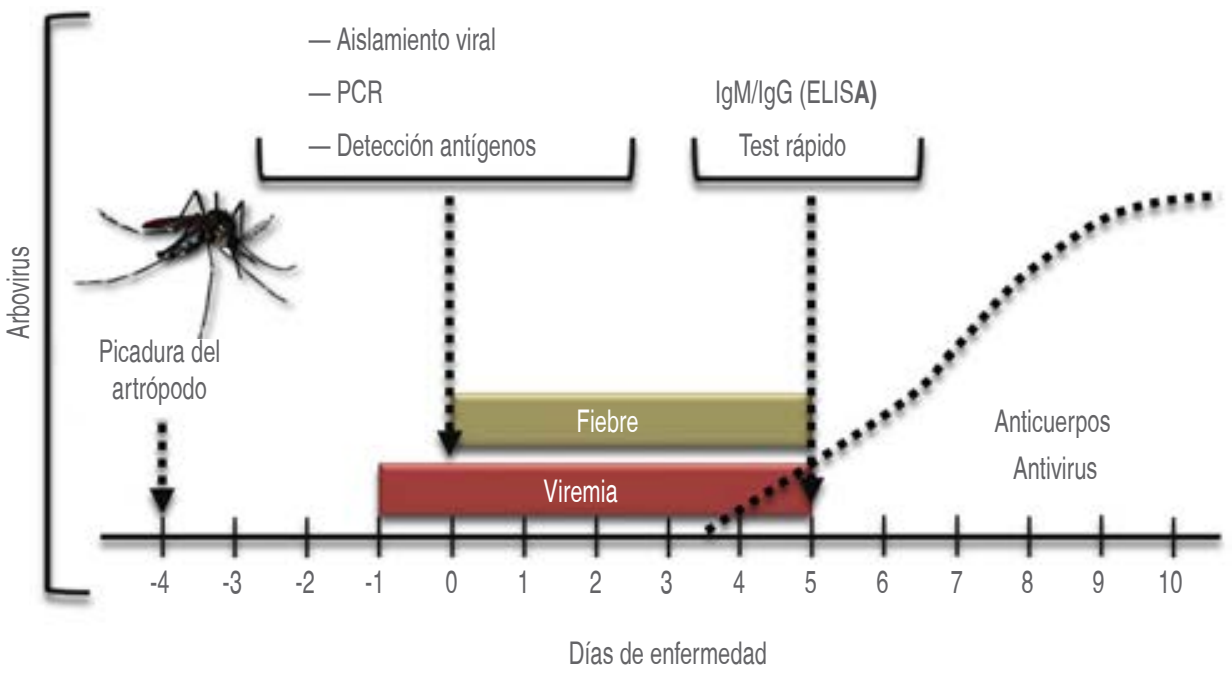

Figura 5:

Diagnóstico sindrómico: curso de la infección y exámenes de laboratorio. Tomado y modificado de: Cabezas C, Donaires F. Enfoque sindrómico para el diagnóstico y manejo de enfermedades infecciosas febriles agudas en situaciones de emergencia. Rev Peru Med Exp Salud Pública. 2017; 34 (2): 316-322. 
caracteriza por la presencia de un cuadro febril que está asociado con una sintomatología inespecífica. En el diagnóstico diferencial de estas enfermedades febriles se encuentran algunas enfermedades de prioridad sanitaria y también otras infecciones cuyo conocimiento todavía es limitado y no se conoce su magnitud en la población. ${ }^{21}$

El MAYV es un patógeno importante, reemergente en la parte norte de Sudamérica; aunque el número de casos reportados y la presencia de brotes de enfermedad artrálgica son esporádicos en comparación con otros arbovirus, es posible que un diagnóstico erróneo considerable y un subregistro puedan conducir a estimaciones inexactas en la carga de la salud pública de este virus. Esta inexactitud se debe a que el diagnóstico preciso de la fiebre por MAYV puede llegar a ser complicado como resultado de la similitud clínica con otros arbovirus endémicos, así como por el desafío que implica la reactividad inmune cruzada en los ensayos de laboratorio con anticuerpos y/o fijación del complemento relacionada con otros alfavirus, como ya se ha mencionado previamente. ${ }^{12,14}$

La detección de anticuerpos y las tasas de aislamiento del virus indican que el MAYV infecta comúnmente a personas que residen cerca de los focos de transmisión. ${ }^{14}$

Existe una subestimación enorme de los casos de fiebre de Mayaro en América del Sur, debido a la amplia superposición de signos y síntomas, los cuales caen por debajo del paraguas del dengue. ${ }^{14}$

El impacto social y económico de la fiebre de Mayaro es menor que el del chikunguña y del dengue, sin embargo, se ha demostrado que turistas que regresan de la región del Amazonas adquieren la infección por MAYV, destacando no sólo la necesidad de considerar la presencia de esta infección en viajeros que regresan febriles, sino también un posible papel en la transmisión y propagación de esta infección a nivel global. De esta manera, los virus pueden viajar en pasajeros infectados, especialmente en aquellos individuos que se encuentran en el periodo de incubación de la enfermedad, lo cual, además, se ve facilitado por las grandes aglomeraciones urbanas, por lo que se incrementan las oportunidades del contagio viral así como la producción de pandemias. ${ }^{15,17,22}$

Finalmente, las arbovirosis emergentes merecen un estudio más serio, porque no todas las fiebres tropicales son causadas por el DENV. La presencia de casos reportados en México y Haití sugieren que el virus está expandiendo su área geográfica de actividad; una de las vías es su «importación» a zonas no endémicas como Francia, Alemania, Países Bajos y Suiza. Mientras las infecciones por DENV, CHIKV y ZIKV se encuentran desenfrenadas extendiéndose por todo el continente, nos deja el siguiente cuestionamiento: ¿será la fiebre de Mayaro la nueva plaga? ${ }^{12,17}$

\section{Referencias}

1. Cabello CC, Cabello CF. Zoonosis con reservorios silvestres: amenazas a la salud pública y a la economía. Rev Méd Chile. 2008; 136: 385-393.

2. Zúñiga $\mathrm{Cl}$, Caro LJ. Virus Mayaro: una nueva amenaza para el continente Americano. Rev Latin Infect Pediatr. 2017; 30 (1): 12-14.

3. Cárdenas MM, Pech SN, Arias LJ. Fiebre Mayaro: enfermedad emergente al acecho. Ciencia Humanismo Salud. 2016; 3 (3): 32-40.

4. Barón CA, Munguía MID. Dengue, chikungunya, zika y Mayaro, amenazas para la salud en Honduras. Rev Fac Cienc Méd. 2017: 44-57.

5. Arévalo CY, Bogotá SM, Cortés PL, Sierra VA, Moscoso J, Méndez WA. Virus Mayaro: un arbovirus que amenaza a Colombia. Revista de Medicina e Investigación UAEMéx. 2017; 5 (2): 98-108.

6. Arredondo GJ, Méndez HA, Medina CH. Arbovirus en Latinoamérica. Acta Pediatr Mex. 2016; 37 (2): 111-131.

7. Muñoz M, Navarro JC. Virus Mayaro: un arbovirus reemergente en Venezuela y Latinoamérica. Biomédica. 2012; 32: 286-302.

8. Wang E, Paessler S, Aguilar PV, Carrara AS, Ni H, Greene IP, Weaver SC. Reverse transcription PCR enzyme linked immunosorbent assay for rapid detection and differentiation of alphavirus infections. J Clin Microbiol. 2006; 44 (11): 4000-4008.

9. Tesh RB, Watts DM, Russell KL, Damodaran C, Calampa C, Cabezas $\mathrm{C}$ et al. Mayaro virus disease: an emerging mosquito-borne zoonosis in tropical South America. Clin Infect Dis. 1999; 28: 67-73.

10. Ríos GC, De Benedictis SG, Chirino CA. Conocimientos, actitudes y prácticas sobre el Virus Mayaro en estudiantes de medicina, 2017. Rev Inst Med Trop. 2018; 13 (1): 32-39.

11. De Thoisy B, Gardon J, Salas RA, Morvan J, Kazanji M. Mayaro virus in wild mammals, French Guiana. Emerging Infectious Diseases. 2003; 9 (10): 1326-1329.

12. Izurieta R, DeLacure D, Izurieta A, Hoare I, Reina OM. Mayaro virus: the jungle flu. Virus Adaptation and Treatment. 2018; 10 : 9-17.

13. Alves ED, Lopes da Fonseca BA. Will Mayaro virus be responsible for the next outbreak of an arthropod-borne virus in Brazil? Braz J Infect Dis. 2017; 21 (5): 540-544.

14. Auguste AJ, Liria J, Forrester NL, Giambalvo D, Moncada M, Long $\mathrm{KC}$ et al. Evolutionary and ecological characterization of Mayaro virus strains isolated during an Outbreak, Venezuela, 2010. Emerg Infect Dis. 2015; 21 (10): 1742-1750.

15. García FM, Moraes FL. Emerging alphaviruses in the Americas: chikungunya and Mayaro. Rev Soc Bras Med Trop. 2014; 47 (6): 677-683.

16. Danillo Lucas Alves E, Benedito Antonio Lopes da F. Characterization of the immune response following in vitro Mayaro and chikungunya viruses (Alphavirus, Togaviridae) infection of mononuclear cells. Virus Research. 2018; 256: 166-173.

17. Mattar VS, González TM. Mayaro y chikungunya; dos alfavirus con similitudes clínicas y epidemiológicas. Rev MVZ Córdoba. 2015; 20 (Supl.): 4861-4863.

18. Long KC, Ziegler SA, Thangamani S, Hausser NL, Kochel TJ, Higgs $\mathrm{S}$, Tesh RB. Experimental transmission of Mayaro virus by Aedes aegypti. Am J Trop Med Hyg. 2011; 85 (4): 750-757. 
19. Cabezas C, Donaires F. Enfoque sindrómico para el diagnóstico y manejo de enfermedades infecciosas febriles agudas en situaciones de emergencia. Rev Peru Med Exp Salud Pública. 2017; 34 (2): 316-322.

20. Alerta Epidemiológica Fiebre de Mayaro. Organización Panamericana de la salud 1 de mayo de 2019.

21. Estudio interinstitucional desarrollado por las instituciones del Ministerio de Salud del Perú, Instituto de Investigación de Enfermedades Tropicales de la Marina de los Estados Unidos,
Universidad Nacional Mayor de San Marcos, Universidad Peruana Cayetano Heredia. Perfil etiológico del síndrome febril en áreas de alto riesgo de transmisión de enfermedades infecciosas de impacto en salud pública en el Perú, 2000-2001. Rev Peru Med Exp Salud Publica. 2005; 22 (3): 165-174.

22. Halsey ES, Siles C, Guevara C, Vilcarromero S, Jhonston EJ, Ramal $\mathrm{C}$ et al. Mayaro Virus Infection, Amazon Basin Region, Peru, 20102013. Emerg Infect Dis. 2013; 19 (11): 1839-1842. 